\title{
Measuring the combinatorial expression of solute transporters and metalloproteinases transcripts in colorectal cancer
}

\author{
Caroline A Kerr*1,2, Robert Dunne ${ }^{1,3}$, Barney M Hines ${ }^{1,4}$, Michelle Zucker ${ }^{1,5}$, \\ Leah Cosgrove ${ }^{1,5}$, Andrew Ruszkiewicz ${ }^{6}$, Trevor Lockett ${ }^{1}$ and Richard Head ${ }^{1}$
}

\begin{abstract}
Address: ${ }^{1}$ CSIRO Preventative Health Flagship, CSIRO Division of Molecular and Health Technologies, CSIRO, Division of Molecular and Health Technologies, Adelaide, SA, 5000, Australia, ${ }^{2}$ CSIRO, Division of Molecular and Health Technologies, North Ryde, NSW, 1670, Australia , ${ }^{3}$ CSIRO, Mathematical and Information Sciences, North Ryde, NSW, 1670, Australia, ${ }^{4}$ CSIRO Division of Livestock Industries, Queensland Biosciences Precinct, St Lucia, Qld, 4067, Australia , ${ }^{5}$ CSIRO, Division of Molecular and Health Technologies, Adelaide, SA, 5000, Australia and ${ }^{6}$ Department of Pathology, The University of Adelaide, Adelaide, SA, 5005, Australia

Email: Caroline A Kerr* - Caroline.Kerr@csiro.au; Robert Dunne - Rob.Dunne@csiro.au; Barney M Hines - Barney.Hines@csiro.au; Michelle Zucker - Michelle.Zucker@csiro.au; Leah Cosgrove - leah.cosgrove@csiro.au;

Andrew Ruszkiewicz - andrew.ruszkiewicz@imvs.sa.gov.au; Trevor Lockett - Trevor.Lockett@csiro.au; Richard Head - Richard.head@csiro.au

* Corresponding author
\end{abstract}

Published: 19 August 2009

BMC Research Notes 2009, 2:164 doi:10.1186/1756-0500-2-164
Received: 13 May 2009

Accepted: 19 August 2009

This article is available from: http://www.biomedcentral.com//756-0500/2/164

(C) 2009 Kerr et al; licensee BioMed Central Ltd.

This is an Open Access article distributed under the terms of the Creative Commons Attribution License (http://creativecommons.org/licenses/by/2.0), which permits unrestricted use, distribution, and reproduction in any medium, provided the original work is properly cited.

\begin{abstract}
Background: It was hypothesised that colorectal cancer (CRC) could be diagnosed in biopsies by measuring the combined expression of a small set of well known genes. Genes were chosen based on their role in either the breakdown of the extracellular matrix or with changes in cellular metabolism both of which are associated with CRC progression

Findings: Gene expression data derived from quantitative real-time PCR for the solute transporter carriers (SLCs) and the invasion-mediating matrix metalloproteinases (MMPs) were examined using a Linear Descriminant Analysis (LDA). The combination of MMP-7 and SLC5A8 was found to be the most predictive of CRC.

Conclusion: A combinatorial analysis technique is an effective method for both furthering our understanding on the molecular basis of some aspects of CRC, as well as for leveraging well defined cancer-related gene sets to identify cancer. In this instance, the combination of MMP-7 and SLC5A8 were optimal for identifying CRC.
\end{abstract}

\section{Findings}

Colorectal cancer is the third-most common cancer in males and second-most common in females worldwide [1]. Its prevalence highlights a need to more deeply understand the molecular interactions that lead to its progression. Two important and well documented pathways in the progression of colorectal cancer are changes in energy source for cellular metabolism and break down of the extracellular matrix.
Healthy colonocytes use short-chain monocarboxylates, in particular butyrate, as their main source of energy [2]. The solute-linked carrier (SLC) SLC5A8, a $\mathrm{Na}^{+}$-coupled transporter, and monocarboxylate transporter (MCT1) SLC16A, are possibly vehicles by which short-chain monocarboxylates are transported into the colonic epithelium [3-5]. SLC5A8 and SLC16A1 have been purported to provide a mechanism for the suppression of tumour growth in colorectal and gastric cancers $[3,6]$ and are 
down-regulated with tumour progression [4]. As colonocytes become cancerous there is a shift in energy source away from butyrate to glucose, resulting in increased levels of glucose in colorectal cancer cells [7] and in carcinomas [8]. Associated with this is an up-regulation of the glucose transporter SLC2A1, which has been shown in a significant proportion of aggressive human tumours [e.g. [9]]. Together, these changes are believed to facilitate tumour growth and proliferation [10].

Matrix metalloproteinases (MMPs) are a family of zincand calcium-dependent proteolytic enzymes that degrade macromolecules of the extracellular matrix. Members of this family, such as MMP-2, -9 and -7 , have been shown to be associated with the breakdown of type IV collagen and the basement membrane. They have been implicated in tumour progression and invasion in human cancer tissues [11-13]. The proteolytic activity of some MMPs (e.g. MMP-2, -9 and -14) can be suppressed by Reversioninducing cysteine-rich protein with kazal motifs (RECK) [14]. Decreased expression of RECK is believed to result in increased invasion, metastasis and angiogenesis [reviewed by [15]] and is associated with poor prognosis in cancer patients [16].

This paper investigates genes in combination from two previous well defined processes in colorectal cancer. The abundance of transcripts from well described candidate genes implicated in either the tumorigenic process or metabolic changes associated with carcinogenesis were examined in human colorectal cancer cell lines and human cancer and healthy colonic tissues. In particular, the expression of the nutrient transporter genes (SLC2A1, SLC16A1 and SLC5A8), genes encoding proteins involved in tissue remodelling and tumour invasion (MMP-2, -7, 9 and -12 , and the MMP regulator RECK), were examined in two sets of normal human colon and colorectal tumour samples and in four human colorectal cancer cell lines. The study used a combinatorial transcript expression bioinformatic approach to leverage described information on a small gene set in order to discriminate between normal and colorectal tumour tissue and help to define interrelationships between processes known to change during carcinogenesis.

\section{Methods \\ Sample collection}

Human colon tissue was sourced from the Division of Tissue Pathology, Institute of Medical and Veterinary Science, University of Adelaide. There were two sets of normal and CRC tissues as outlined in Table 1 (for further details of these samples [see Additional file 1 Tables S1 and S2].

\section{Total RNA extraction, cDNA synthesis and real-time PCR}

The human tissue samples were obtained from resections of specimens and placed in OCT (optimal cutting temperature cryopreservation medium) [17], snap-frozen in liquid nitrogen and then stored at $-86^{\circ} \mathrm{C}$. After histological verification RNA was extracted by placing samples in $1 \mathrm{ml}$ of Trizol ${ }^{\circledast}$ Reagent (Invitrogen, Sydney, Australia), then homogenised using beads (mix of $2.5 \mathrm{~mm}$ glass and 0.1 $1.0 \mathrm{~mm}$ diameter silicon-zirconium beads) in a MiniBeadbeater- $8^{\mathrm{TM}}$ (BioSpec Products Inc., Oklahoma, USA) and extracted according to Invitrogen's instructions. Samples were then further processed using RNAeasy mini spin columns (QIAGEN, Doncaster, Australia) with contaminating DNA being removed via DNase on-column digestion as per the manufacturer's instructions. Similarly, cultured cells that were at least $70 \%$ confluent were extracted directly using the RNAeasy spin columns. The integrity of RNA samples from Study 2 and the cell lines were checked using a Bioanalyzer 2100 (Agilent Technologies) [18]. All of the RNA samples were then quantified using a NanoDrop $^{\circledast}$ ND-1000 Spectrophotometer. Samples were then diluted to100 ng/ul.

cDNA was synthesised using SuperScript II (Invitrogen) reverse transcriptase (Invitrogen) using 1 ug of RNA per $20 \mathrm{uL}$ reaction and incubated as outlined in the manufacturer's instructions. Real-time PCR assays were conducted using off-the shelf optimised and guaranteed TaqMan ${ }^{\circledast}$ Gene Expression Assays (Applied Biosystems, Foster City, California, USA), that consisted of primers and a probe for the specific genes (Table 2). Three housekeeping genes were used: the conventional reference gene $18 \mathrm{~S}$ ribosomal RNA (18S) [e.g. [19]], as well as a ribosomal protein (large P0, a component of the 60S subunit) and HUWE1 (see Table 2). The latter two were identified as suitable using a

Table I: Summary of tissue sample details^

\begin{tabular}{|c|c|c|c|c|c|c|}
\hline & \multirow[t]{2}{*}{ Site } & \multirow[t]{2}{*}{ Normal } & \multicolumn{4}{|c|}{ Tumour pathology } \\
\hline & & & Dukes A & Dukes B & Dukes C & Dukes D \\
\hline \multirow[t]{2}{*}{ Study I } & Left & 4 & 2 & 1 & 2 & - \\
\hline & Right & I & 2 & - & 2 & - \\
\hline \multirow[t]{3}{*}{ Study 2} & Left & 6 & 1 & 4 & 2 & - \\
\hline & Right & 6 & 1 & 4 & - & 1 \\
\hline & Transverse & 2 & - & - & I & - \\
\hline
\end{tabular}

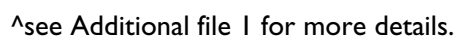


Table 2: Gene and assay details.

\begin{tabular}{|c|c|c|c|}
\hline Gene Name and Symbol & Genbank accession numbers & TaqMan Primer/Probe ID & $\begin{array}{l}\text { Product size } \\
\text { (bp) }\end{array}$ \\
\hline Eukaryotic I8S rRNA. & $\underline{\times 03205.1}$ & Hs9999990I_sl & 187 \\
\hline HECT, UBA and WWE domain containing I (HUWEI). & $\begin{array}{l}\text { NM } 031407 \\
N M \quad 005703 \\
N M \quad 017627 \\
X M \quad 497119\end{array}$ & $\mathrm{Hs} 00328354 \_\mathrm{ml}$ & 74 \\
\hline Ribosomal protein, large, PO (60s). & $\frac{\text { NM } 053275.3}{\text { NM } 0011002.3}$ & Hs99999902_ml & 105 \\
\hline Matrix metalloproteinase I2 (MMPI2). & NM 002426 & $\mathrm{Hs} 00 \mathrm{I} 59 \mathrm{I78} \_\mathrm{ml}$ & 62 \\
\hline $\begin{array}{l}\text { Matrix metalloproteinase } 2 \text { (MMP2) (gelatinase A, } 72 \mathrm{kDa} \\
\text { gelatinase, } 72 \mathrm{kDa} \text { type IV collagenase). }\end{array}$ & NM 004530 & $\mathrm{Hs} 00234422 \_\mathrm{ml}$ & 83 \\
\hline Matrix metalloproteinase 7 (MMP7). & NM 002423 & Hs00I59I63_ml & 101 \\
\hline $\begin{array}{l}\text { Metalloproteinase } 9 \text { (MMP9)(gelatinase B, } 92 \text { kDa gelatinase, } 92 \\
\text { kDa type IV collagenase). }\end{array}$ & NM 004994 & $\mathrm{Hs} 00234579 \_\mathrm{ml}$ & 54 \\
\hline $\begin{array}{l}\text { Reversion-inducing-cysteine-rich protein with kazal motifs } \\
\text { (RECK). }\end{array}$ & NM 021111 & $\mathrm{Hs} 00221638 \_\mathrm{ml}$ & 76 \\
\hline $\begin{array}{l}\text { Solute carrier family } 2 \text { (facilitated glucose transporter) member } \\
\text { I: SLC2AI, alias Glut I. }\end{array}$ & NM 006516 & $\mathrm{Hs00I97884 \_ ml}$ & 70 \\
\hline Solute carrier family 5 (iodide transporter), member 8. & NM 145913 & Hs00377618_ml & 88 \\
\hline $\begin{array}{l}\text { Solute carrier family 16, member I (monocarboxylic acid } \\
\text { transporter I). }\end{array}$ & NM 003051 & $\mathrm{Hs} 00161826 \_\mathrm{ml}$ & 110 \\
\hline
\end{tabular}

commercial database from Gene Logic (Gaithersburg, Maryland, U.S.A.). The database contains information on 44928 probe-sets (HUG-133A and B Affymetrix arrays) derived from 462 individuals covering the classes: normal 222; adenoma 29; cancer 161; and other disease 50. The dataset was normalized using the GCRMA algorithm [20] and then probe-sets were selected that had minimal variance across all arrays and had appreciable expression levels. The aim was to use three housekeeping genes of varying abundance (18s as the highest and HUWEI as the lowest) to cover the range of target transcript differential expression. Also, the target and housekeeping gene assays were selected where possible to prime over an intron-exon boundary to avoid amplifying any contaminating genomic DNA (which could otherwise bias results). The assays were then set up in four aliquots per cDNA sample using TaqMan ${ }^{\circledast}$ Universal PCR Master Mix commensurate with the manufacture's instructions, except that $5 \mu \mathrm{l}$ reaction volumes were used. Assays consisted of $20 \times$ mix of unlabeled PCR primers and TaqMan ${ }^{\circledast}$ MGB probe (FAM dye-labelled). Assays were run in 384-well plates on an Applied Biosystems PRISM ${ }^{\circledast} 7900$ HT real-time thermocycler and analysed using Sequence Detection System software (version 2.3) as outlined in the TaqMan ${ }^{\circledR}$ Gene Expression Assays protocol.

\section{Data acquisition}

Data on the expression levels of target and reference genes were obtained in the form of crossing points [21] or threshold $(\mathrm{Ct})$ values. The target genes were then analysed following the delta-delta $\mathrm{Ct}$ value procedure $[22,23]$ with the assumption that efficiency was $100 \%$ and amplicons doubled each cycle. Briefly, the Ct for each housekeeping gene (HK) was subtracted from each corresponding target gene such that,

$$
\Delta \mathrm{Ct}_{\text {normalised target gene }}=\mathrm{Ct}_{\text {target gene }}-\mathrm{Ct}_{\mathrm{HK} \text { gene }},
$$

The mean of the normal tissues was used to create a reference tissue value. So,

$\Delta \mathrm{Ct}_{\text {reference }}=1 / \mathrm{n} \sum_{\text {all normal tissues }}\left[\mathrm{Ct}_{\text {target (gene normal tissue) }}-\mathrm{Ct}_{\mathrm{HK} \text { gene, }}\right]$

and then,

$$
\Delta \Delta \mathrm{Ct}=\Delta \mathrm{Ct}_{\text {normalised target gene }}-\Delta \mathrm{Ct}_{\text {reference }} .
$$

This process allowed for the data to be analysed for artefacts, real-time PCR repeatability and stability of HK expression. As three HK genes were used, the process was then repeated with each housekeeping gene and the median calculated; the ratio of the gene expression is $2^{-}$ $\Delta \Delta \mathrm{Ct}$.

The normalised $\Delta \Delta \mathrm{Ct}$ data sets were then combined and all subset variable selection with Linear Discriminant Analysis (LDA) was performed to ascertain the best combination of transcripts that separated tumour from normal. The error rate for the model was estimated using 'leave-one-out estimates' for cross validation [24].

Transcript expression from cultured colorectal cancer cell lines (HT29, HCT116, Caco2 and LIM1215) was then used to further test the optimal combinations using LDA. 
The effect of tissue sampling site (i.e. left, transverse or right colon), the type of 'normal' and Dukes stage was also analysed.

\section{Results}

The normalised data sets for all seven target genes for study 1 , which consisted of randomly grouped tumour and normal, were analysed using LDA [see Additional file 1 for figure S1, Additional file 2 for the raw Ct values], resulting in a separation of the normal and tumour samples (the leave-one-out error estimate from the LDA is 0.25 , [see Additional file 1 - Figure S2]. Using an all subsets variable selection procedure with LDA created a reduced model using only RECK and MMP-7 (see Figure 1 ), giving an improved leave-one-out error estimate of 0.06. Note, all the 'normal' samples clustered together regardless of their source (i.e. from a CRC or healthy patient). Therefore, there was no effect by the source of 'normal'.

For study 2, which consisted of paired data, the normalised data sets for all seven target genes were then analysed using LDA [see Additional file 1 - Figure S3 and Additional file 3 for raw Ct values], resulting in separation of the normal and tumour samples (the leave-one-out error estimate from the LDA is 0.178 , [see Additional file 1 figure S4]. This separation was further increased using an all subsets variable selection procedure with LDA. The resultant reduced model, this time using only MMP7 and

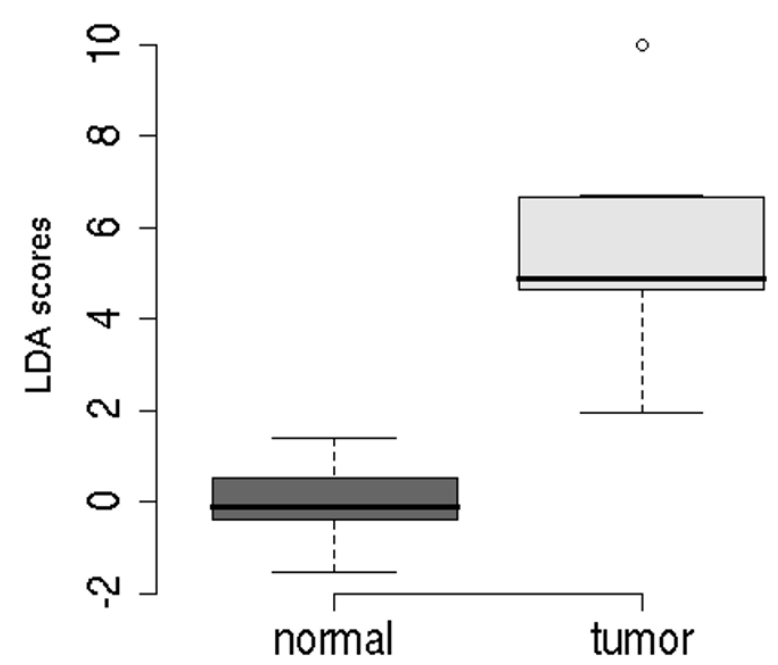

Figure I

Box plot of the optimal transcript model for separating normal (healthy) and tumour colon tissue from Study I. LDA scores resulted from the combined normalised gene data set reduced down to an optimal model of RECK and MMP-7.
SLC5A8, had a leave-one-out error estimate from the LDA of 0.035 (see Figure 2).

When data from both the human tissue studies were combined and LDA applied to the four classes (Study 1 normal, Study 1 tumour, Study 2 normal, Study 2 tumour); the two sets of 'normals' could not be separated and the two sets of 'tumours' could not be separated. This indicates that it is feasible to combine the studies. The optimal transcript combination that separated tumour from normal was SLC5A8 and MMP-7 (see Figure 3) resulting in a leave-one-out error estimate of 0.128 . There was no effect of sampling site (i.e., left, right or transverse colon) or Duke's stage on the expression of MMP-7 or SLC5A8.

Then, as an exercise to test the mathematics of this approach, the two studies plus CRC cell line data [see Additional file 1 for Figure S5 and Additional file 3 for raw $\mathrm{Ct}$ values] were then combined. The maximum separation between tissue types (normals, as opposed to tumour tissue plus cell lines) occurred with the transcript combination of MMP-7, RECK and SLC5A8 (see Figure 4).

\section{Discussion}

This communication investigated expression patterns of transcripts associated with processes involved in the development of colorectal cancer. Genes examined were the solute transporters SLC2A1, SLC5A8 and SLC16A1, which are associated with changes in the cellular import

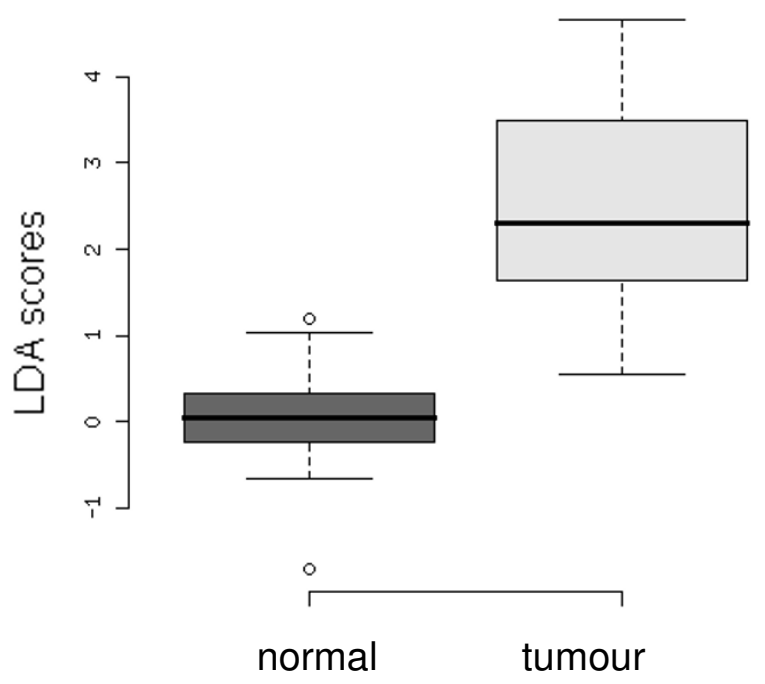

\section{Figure 2}

Box plot of the optimal transcript model for separating normal (healthy) and tumour colon tissue from Study 2. LDA scores resulted from the combined normalised gene data reduced down to an optimal model of MMP7 and SLC5A8. 


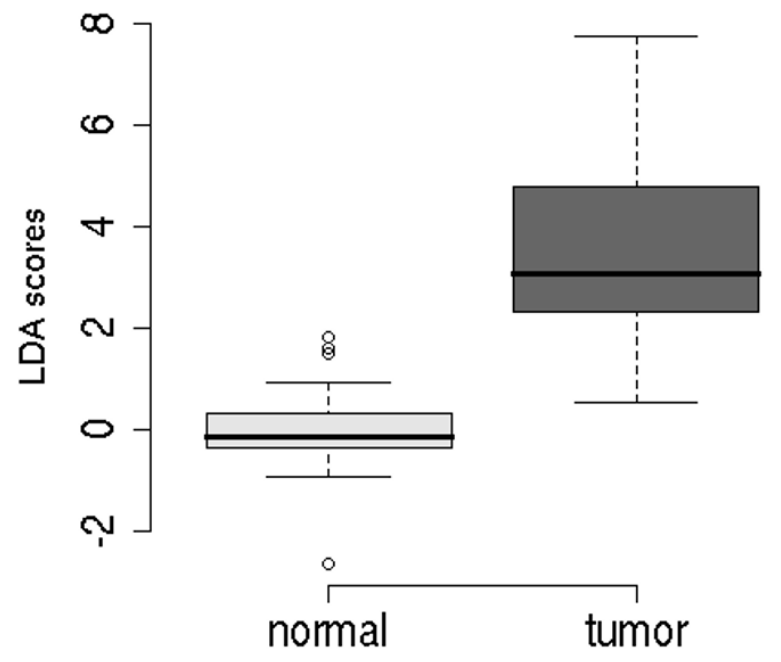

Figure 3

Box plot of the optimal transcript model for separating normal (healthy) and tumour colon tissue from Studies I and 2. LDA scores resulted from the combined normalised gene data set reduced down to an optimal model of MMP7 and SLC5A8.

of energy sources, and MMP-2, MMP-7, MMP-9 and MMP-12, which are related to the breakdown of the extracellular matrix, and the MMP negative regulator, RECK. Individual differential gene expression patterns were established for normal and cancerous tissue samples. When the data were combined, a combination of MMP-7 and SLC5A8 (and, to a lesser extent, RECK) provided the greatest separation between healthy colon tissue and colorectal cancer (tissue or cell lines). One possible interpretation of these results is that the mechanisms which act to break down the extracellular matrix and promote tumour invasion also induce MMP negative regulation. Whilst in parallel, SLC5A8 levels in tumours were reduced compared to normal tissue and cell lines, which is consistent with previous studies [4] showing an association between SLC5A8 down-regulation and tumour progression.

This study has demonstrated that it is advantageous to use a combinatorial approach to defining biomarkers of carcinogenesis processes compared to using individual candidate transcript markers. Others have used systematic approaches when analysing transcripts for cancer biomarkers (e.g. pancreatic cancer by [25]) and have shown that markers, which individually are suboptimal, can be combined to yield higher sensitivity and specificity. Even though our study uses a small patient tissue library, it demonstrates a proof-of-concept for the combinatorial

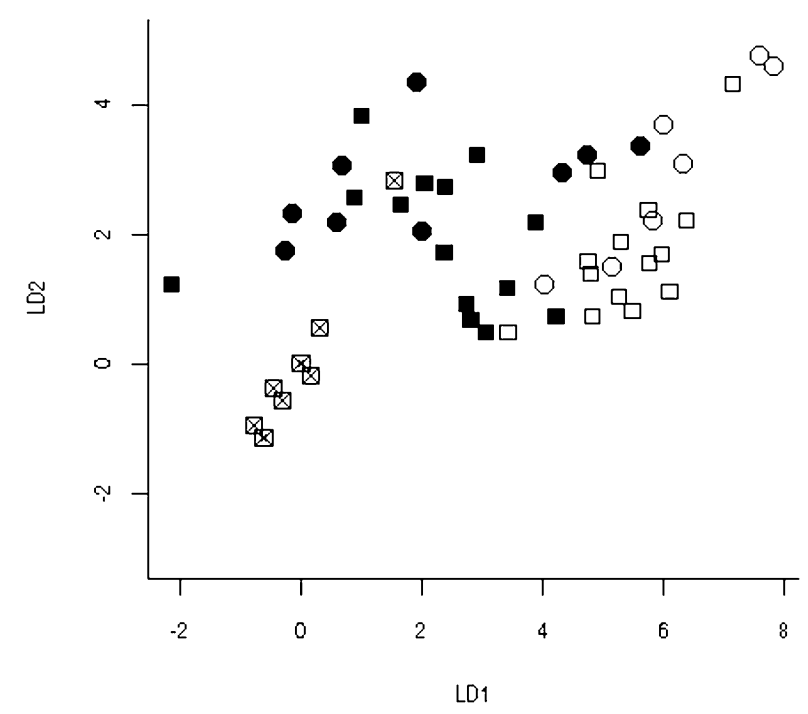

Figure 4

The first two Linear Discriminants (LDI and LD2) from Linear Discriminant Analysis (LDA) of the combined normalised gene data sets. Reduced down to an optimal model with the transcript combination of MMP7, SLC5A8 and RECK which separated the normal (healthy) and the tumour colon tissue from Studies I and 2 and the cultured cell lines of ('empty circle' Study I normal, 'empty square' Study 2 normal, 'black circle' Study I tumour, 'black square' Study 2 tumour, 'black square with cross' cell lines).

approach to transcript biomarkers that now needs to be validated in larger controlled data sets $[26,27]$. In addition, our technique may prove useful to validate other colorectal cancer candidate transcripts, such as those defined in a recent study [28] which applied a meta-analysis or genome wide studies (e.g. microarrays) to comprehensively evaluate microarray data for biomarkers. Although using tumour-related gene expression may not be an optimal platform for colorectal cancer detection, this combinatorial approach demonstrates a method for biomarker discovery based on a priori hypotheses originating from other studies that may prove useful either in elucidating early biomarkers or in establishing auxiliary markers of prognosis. This approach could be applied in the clinical setting to increase the sensitivity and specificity of biomarkers by combining the analyses with other markers [29].

\section{Competing interests}

The authors declare that they have no competing interests.

\section{Authors' contributions}

$\mathrm{CK}$ designed the study and co-authored the manuscript with RD, BMH, LC, MZ, AR, TL and RH. BMH and MZ per- 
formed the molecular work. RD performed the mathematical and statistical analysis. AR provided the clinical guidance, pathology details and sourced and prepared the tissue samples. TL and RH sought the funding. All authors read and approved the final manuscript.

\section{Additional material}

\section{Additional file 1}

Further breakdown and details of tissue and cell expression data. Further details on the methods and results used in this study. Contains Tables S1 and S2 and Figures S1-S5.

Click here for file

[http://www.biomedcentral.com/content/supplementary/17560500-2-164-S1.doc]

\section{Additional file 2}

Table of PCR Ct values for the house keeper genes 18s, HUWE1 and RPO and target genes MMP2, MMP12, MMp7, MMP9, RECK, SLC2A1, SLC5A8 and SLC16A1 for study1 and Cell lines (Caco2, HT29, HCT116 and LIMS1215). Worksheets containing raw Ct values for house keeper and target genes for study 1 (unpaired data) and cell lines.

Click here for file

[http://www.biomedcentral.com/content/supplementary/17560500-2-164-S2.xls]

\section{Additional file 3}

Table of PCR Ct values for the house keeper genes 18s, HUWE1 and RPO and traget genes MMP2, MMP12, MMp7, MMP9, RECK, SLC2A1, SLC5A8 and SLC16A1, for Study 2. Worksheets containing raw Ct values for house keeper and target genes for study 2 (paired data). Click here for file

[http://www.biomedcentral.com/content/supplementary/17560500-2-164-S3.xls]

\section{Acknowledgements}

This research was funded by CSIRO's Preventative Health Flagship program. We would like to thank Siok Hwee Tan for her laboratory assistance and Peter Molloy, Lloyd Graham and Andre-Denis Wright for their manuscript critique.

\section{References}

I. Parkin DM, Bray F, Ferlay J, Pisani P: Global cancer statistics, 2002. CA-A Cancer J Clinicians 2005, 55:74- 108.

2. Wong JMW, de Souza R, Kendall CWC, Emam A, Jenkins DJA: Colonic health: Fermentation and short chain fatty acids. J Clin Gasterol 2006, 40:235-243.

3. Gupta N, Martin PM, Prasad PD, Ganapathy V: SLC5A8 (SMCTI)mediated transport of butyrate forms the basis for the tumor suppressive function of the transporter. Life Sci 2006 , 78:2419-2425

4. Paroder V, Spencer SR, Paroder M, Arango D, Schwartz S Jr, Mariadason JM, Augenlicht LH, Eskandari S, Carrasco N: $\mathbf{N a ( + ) / m o n o c a r - ~}$ boxylate transport (SMCT) protein expression correlates with survival in colon cancer: Molecular characterization of SMCT. J Proc Natl Acad Sci USA 2006, 103:7270-7275.

5. Iwanaga T, Takebe K, Kato I, Karaki SI, Kuwahara A: Cellular expression of monocarboxylate transporters (MCT) in the digestive tract of the mouse, rat, and humans, with special reference to slc5a8. Biomed Res-Tokyo 2006, 27:243-254.
6. Ganapathy V, Gopal E, Miyauchi S, Prasad PD: Biological functions of SLC5A8, a candidate tumour suppressor. Biochem Soc $T$ 2005, 33:237-240.

7. He L, Li X, Luo HS, Rong H, Cai J: Possible mechanism for the regulation of glucose on proliferation, inhibition and apoptosis of colon cancer cells induced by sodium butyrate. World J Gastroenterol 2007, 13:4015-4018.

8. Haber RS, Rathan A, Weiser KR, Pritsker A, Itzkowitz S, Weiss A, Bodian C, Burstein DE: GLUT-I glucose transporter: A marker of poorer prognosis in colon carcinoma [abstract]. Laboratory Investigation 1997, 76:316.

9. Younes M, Lechago LV, Lechago J: Overexpression of the human erythrocyte glucose transporter occurs as a late event in human colorectal carcinogenesis and is associated with an increased incidence of lymph node metastases. Clin Cancer Research 1996, 2:115I-1154.

10. Macheda ML, Rogers S, Best JD: Molecular and cellular regulation of glucose transporter (GLUT) proteins in cancer. J Cell Physiol 2005, 202:654-662.

II. Hilska M, Roberts PJ, Collan YU, Laine VJO, Kossi J, Hirsimaki P, Rahkonen O, Laato M: Prognostic significance of matrix metalloproteinases- I,-2,-7 and- 13 and tissue inhibitors of metalloproteinases-1,-2,-3 and-4 in colorectal cancer. Inter J Cancer 2007, I 2 I:7| $4-723$

12. Gentner B, Wein A, Croner RS, Zeittraeger I, Wirtz RM, Dimmler A, Dorlaque L, Hohenberger W, Hahn EG, Brueckl WM: Differences in the Gene Expression Profile of Matrix Metalloproteinases (MMPs) and their Inhibitors (TIMPs) in Primary Colorectal Tumors and their Synchronous Liver Metastases. Anticancer Res 2009, 29:67-74.

13. Herszenyi L, Sipos F, Galamb O, Solymosi N, Hritz I, Miheller P, Berczi L, Molnar B, Tulassay Z: Matrix metalloproteinase-9 expression in the normal mucosa-adenoma-dysplasia-adenocarcinoma sequence of the colon. Path \& Oncol Res 2008, 14:3I-37.

14. Takagi S, Simizu S, Osada H: RECK Negatively Regulates Matrix Metalloproteinase-9 Transcription. Cancer Res 2009, 69:1502-1508.

15. Noda M, Takahashi C: Recklessness as a hallmark of aggressive cancer. Cancer Sci 2007, 98:1659-1665.

16. Takeuchi T, Hisanaga M, Nagao M, Ikeda N, Fujii H, Koyama F, Mukogawa T, Matsumoto H, Kondo S, Takahashi C, Noda M, Nakajima Y: The membrane-anchored matrix metalloproteinase (MMP) regulator RECK in combination with MMP-9 serves as an informative prognostic indicator for colorectal cancer. Clin Can Res 2006, 10:5572-5579.

17. Loken SD, Demmetrick DJ: A novel method for freezing and storing research tissue bank specimens. Hum Pathol 2005, 36:977-980.

18. Fleige S, Walf $\bigvee$, Huch S, Prgomet C, Sehm J, Pfaffl MW: Comparison of relative mRNA quantification models and the impact of RNA integrity in quantitative real-time RT-PCR. Biotechnology Letters 2006, 28:1601-1613.

19. Nolan T, Hands RE, Bustin SA: Quantification of mRNA using real-time RT-PCR. Nature Protocols 2006, I:I559-I582.

20. Wu Z, Irizarry RA, Gentleman R, Murillo FM, Spencer F: A model based background adjustment for oligonucleotide expression arrays. Johns Hopkins University, Dept of Biostatistics Working Papers. Working Paper I. [serial on the internet] 2004 [http:/l www.bepress.com/jhubiostat/paper I/].

21. Rasmussen R: Quantification on the LightCycler instrument. In Rapid cycle real-time PCR Edited by: Meur SC, Wittwer C, Nakagawara K. New York: Springer; 200I:2I-34.

22. Schmittgen TD, Livak KJ: Analyzing real-time PCR data by the comparative C-T method. Nature protocols 2008, 3: I I0I-I 108.

23. Yuan JS, Reed A, Chen F, Stewart CN: Statistical analysis of realtime PCR data. BMC Bioinformatics 2006, 7:85.

24. Hirst D: Error-rate estimation in multiple-group linear discriminant analysis. Technometrics 1996, 38:389-399.

25. Firpo MA, Gay DZ, Granger SR, Scaife CL, DiSario JA, Boucher KM, Mulvihill SJ: Improved diagnosis of pancreatic adenocarcinoma using haptoglobin and serum amyloid $A$ in a panel screen. World J Surgery 2009, 33:716-722.

26. Brenner DE, Normolle DP: Biomarkers for the cancer risk, early detection, and prognosis: The validation conundrum. Cancer Epidemiol Biomarkers Prev 2007, 16:1918-1920. 
27. Vineis P, Perera F: Molecular epidemiology and biomarkers in etiologic cancer research: The new in light of the old. Cancer Epidemiol Biomarkers Prev 2007, 16:1954-1965.

28. Chan SK, Griffith OL, Tai IT, Jones SJM: Meta-analysis of colorectal cancer gene expression profiling studies identifies consistently reported candidate biomarkers. Cancer Epidemiol Biomarkers Prev 2008, 17:543-552.

29. Gupta AK, Brenner DE, Turgeon DK: Early detection of colon cancer - New tests on the horizon. Mole Diagnosis \& Therapy 2008, I 2:77-85.

Publish with Biomed Central and every scientist can read your work free of charge

"BioMed Central will be the most significant development for disseminating the results of biomedical research in our lifetime. " Sir Paul Nurse, Cancer Research UK Your research papers will be:

- available free of charge to the entire biomedical community

- peer reviewed and published immediately upon acceptance

- cited in PubMed and archived on PubMed Central

- yours - you keep the copyright 